\title{
Nurses' perceptions of their own level of competence
}

Annette Mollerup, RN, CCRN Herlev University Hospital, Herlev, Denmark * Pernille Skovby Mortensen, RN, CCRN Glostrup University Hospital, Glostrup, Denmark

E-mail: amollerup@yahoo.dk pernillem_dk@yahoo.dk

Key words: competence intensive care experience nurses

\section{SUMMARY \\ * $\quad$ Pressure from the demands of the clinical environment and a lack of experienced staff mean that inexperienced nurses may work outside their own sphere of competence. \\ * Competence appears to be measured through length of employment instead of through professional ability. \\ * Inexperienced nurses find it easier to focus on the technical equipment rather than to try and develop a relationship with a sedated and non-communicative patient.}

\section{INTRODUCTION}

Observations and reflection on practice can often be the stimulus for an investigation. This article explains how a specific set of circumstances and observations instigated a study that served to describe, inform and develop local practice. The project was conducted in 2001 at the intensive care unit (ICU) in Bispebjerg University Hospital, Copenhagen, Denmark. We had worked in this unit for a number of years and were clinical nurse specialists at the time of the study.

The unit had six beds, but for a number of years this was reduced to four due to a shortage of nurses. The main reason for the poor recruitment and retention of nursing staff was the relocation of several key services to other local hospitals. This led to a large number of experienced staff leaving; the majority of those remaining had little or no intensive care nursing experience. This created a situation where a small group of experienced nurses were supervising a large group of inexperienced nurses. Those new to intensive care nursing undertook a unit-based introduction programme lasting approximately one month, after which they were expected to participate fully in the care of patients.

During this time we noticed a change in atmosphere and culture in the unit. The general noise level increased, communication with patients appeared to diminish and the inexperienced nurses showed limited ability to understand the needs of patients. They concentrated on the technological aspects of care at the expense of meeting the psychological needs of the patients. This element of care is crucial for maintaining the well-being of the critically ill, as it is well known that the intensive care environment is stressful for patients (Hudak and Gallo, 1994; Tanimoto et al., 1999; McGuire et al., 2000). The literature confirmed our assumptions that inex- perienced nurses find it easier to focus on the technical equipment rather than on trying to develop a relationship with a sedated and non-communicative patient (Benner, 1995; Plough Hansen, 1995; Gjengedal, 1994).

\section{THE STUDY}

The objective of the study was to describe the perceived level of competence among nurses working in the ICU. We based our work on the following assumptions:

1. The substantial technology in an ICU, combined with the need for a fast introduction and education to intensive care nursing, can lead the inexperienced nurse to feel that basic/essential nursing care knowledge is secondary.

2. Inexperienced nurses are often left alone with complex tasks, with little assistance or guidance.

3. Working up to or beyond a sphere of competency can lead to inexperienced nurses feeling worthless and insecure.

4. Inexperienced nurses do not always recognise the implications of working outside boundaries of competence.

The project investigated the nurses' opinions of their own levels of competence. Similar studies have been conducted and were used as a reference point for this work (Fjelland, 1995; Fredriksen and Dreyer, 1999; Todres et al., 2000).

\section{Methods}

A questionnaire and a focus group were used as the tools of data collection. The questionnaire was distributed to all the nurses working in the unit. It consisted of a combination of open questions (for example, 'Use three words to describe a competent ICU nurse' or 'Which clinical background do you value as necessary before starting as an ICU nurse?') and closed questions (for example, 'Have you experienced situations where you have felt that you crossed the line of your competence?'). The questionnaire also asked for demographic information, such as age and length of experience, which allowed us to create a staff profile. There was an opportunity for the nurses to add any additional comments that they wished to make. Based on the analysis of the answers from the questionnaires, a topic guide was created which was used in the focus group interview (see Figure 1.) 


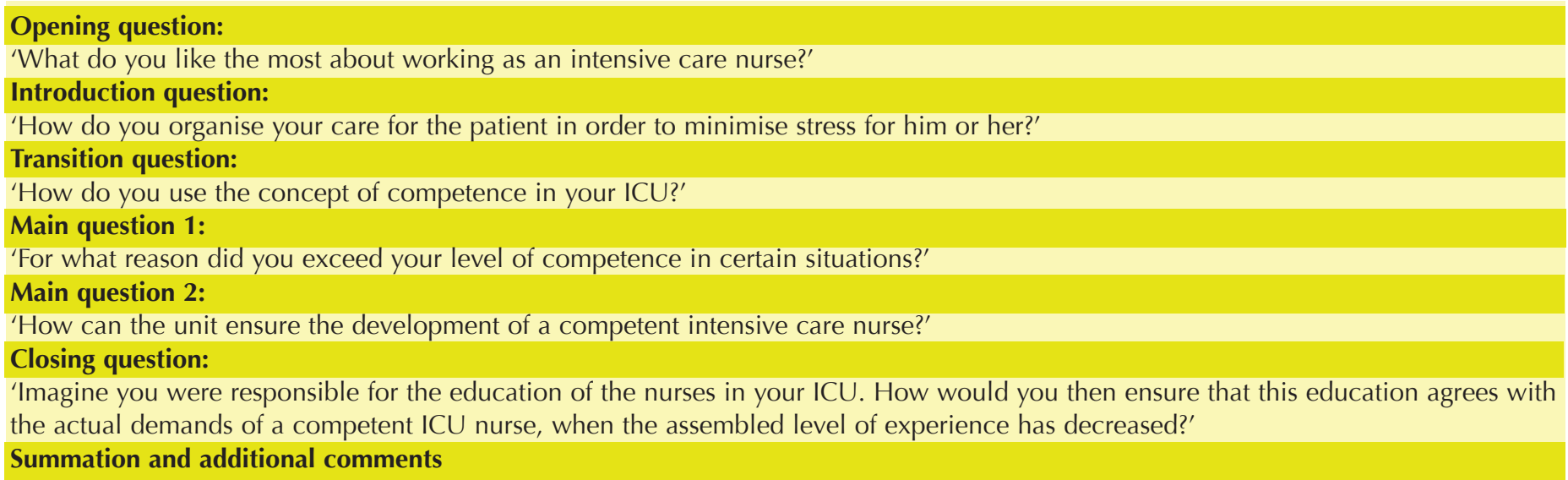

Figure 1. Focus group interview topic guide

Six nurses were invited to participate in a focus group interview. The group was representative of the unit nursing staff profile in terms of gender, age and experience. All participants were reminded that all contributions were welcome and that the discussion should remain confidential to the group within the room. Both in the questionnaire and in the focus group interview we pointed out that none of the participants would be identified in the final report.

The interview lasted for one and a half hours. Immediately following the interview we held a short debriefing with our supervisor and documented our immediate reflections on the statements from the interviewed nurses. The interview tape was transcribed and analysed, and the following discussion presents an overview of the findings.

\section{RESULTS AND DISCUSSION}

The questionnaire

Thirty-one questionnaires were distributed and 26 returned, giving a response rate of $86 \%$. Table 1 shows the distribution of length of experience among respondents.

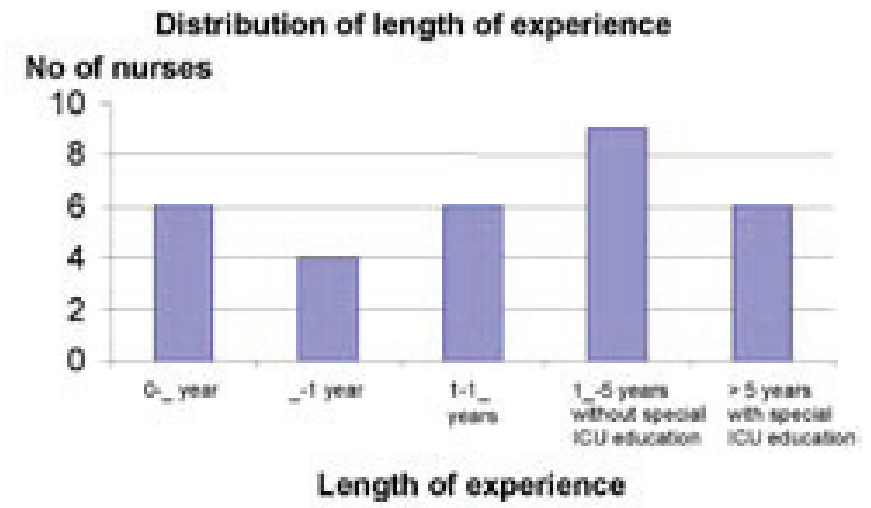

Table 1. Distribution of length of experience among the nurses in this study

The key findings from the questionnaire are outlined below. When nurses were asked to use three words to describe a competent ICU nurse, most of them used words and phrases to reflect decisionmaking skills, knowledge base and being able to have a broad view of the unit as a whole. The majority of respondents identified the need for further qualifications beyond basic training prior to commencing work in an intensive care setting, and $81 \%(n=21)$ felt they had worked outside their own sphere of competence. The five respondents who did not feel that they exceeded their sphere of competency had all worked in the unit for a long time and were all specially educated ICU nurses. In general, the questionnaire responses suggested that nurses should have between one and one and a half years of ICU experience before training and mentoring newly employed nurses.

Sixty five percent $(n=17)$ of the respondents stated that one of the most important qualifications to have before starting in the ICU was experience on a hospital ward. In addition to basic nursing education, working in an intensive care unit in Denmark requires a minimum of two years' clinical experience on relevant wards before joining the ICU. The first six months of employment in an ICU are meant to be an introduction to intensive care nursing. After this period, the nurse is expected to begin specialist education, which consists of a formal seven-week course outside the ICU. The course is not university-based but the content and requirements are the same across all units in Denmark.

Using an adaptation of the work of Patricia Benner (Benner, 1985), a competency ladder was developed (see Figure 2). The researchers then assigned staff to a point on the ladder that described their level of educational attainment and general level of competency as perceived by the researchers (see Table 2).

$\begin{array}{ll}\text { Novice } & \text { Has just begun working in the ICU, is on an } \\ \text { induction period. Needs factual and theoretical } \\ \text { information. Spends a lot of time getting } \\ \text { acquainted with surveillance and other } \\ \text { technical equipment. } \\ \text { Has around six months' experience in the ICU. } \\ \text { Advanced } & \text { Can deliver individual patient care but finds it } \\ \text { beginner } & \text { difficult to assess complex ICU patients and } \\ & \text { is still in need of guidance and help from the } \\ \text { experienced ICU nurse. } & \\ \text { Competent } & \text { Has two or more years' experience in the ICU. } \\ & \text { Has passed the seven-week theory course. Acts } \\ & \text { deliberately and plans work in an efficient and } \\ & \text { meaningful way. Is confident in actions and } \\ \text { can deal with complex ICU patients. } \\ \text { Proficient }\end{array}$


patients. Adopts a patient-centred focus to nursing actions. Has a highly developed view of the clinical area and its demands. Is able to supervise and teach other nurses.

Expert Has completed the specialised education, has more than five years' experience in ICU. Is less dependent on regulations and machinery. Can cope with the demands of patients, relatives and colleagues. Is able to manage complex clinical situations and supervises and teaches others. Able to manage the demands of the clinical environment as a whole.

Figure 2. Competency Ladder (adapted from the work of Benner 1985)

Total number of nurses: $\mathbf{3 1}$
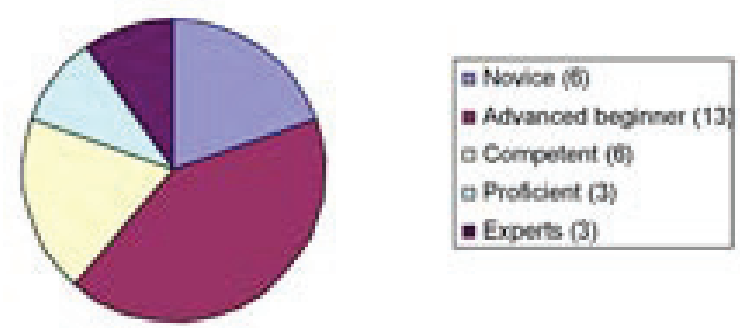

Table 2. Distribution of competency among the nurses in the unit

\section{The focus group interview}

The responses from the focus group interviews indicated that there was very little or no theoretical teaching in the unit. This was due to a shortage of staff and pressure of work. In general, all the nurses expressed the need for a clinical supervisor or educator, whose role would be to ensure that the nurses were working within their own level of competence and to provide education and support. The interviewed nurses considered it very important to have time for reflection and instruction, both as a group and on an individual level.

Most of the nurses in the focus group interview appeared to have worked alone caring for a patient shortly after being introduced to the unit. It seems that nurses were expected to take care of an ICU patient alone after only a short period of time without having the real competence to do so.

The inexperienced nurses felt that they had been given too great a responsibility for their level of competency but felt powerless to do anything about the situation. None of the nurses expressed any kind of psychological stress due to the lack of support; this may have been due to not wanting to appear 'weak' or 'inadequate' in front of colleagues in the focus group interview.

When discussing the stressful nature of the intensive care environment for the patient, the nurses seemed to avoid acknowledging the need to communicate and be with patients. The main topic seemed to be the use of the radio to provide background noise or distraction. One of the participants stated:

'Which is best: Sky Radio or Voice? The patient won't give any appreciation to this. That's why you just tune in to what you yourself find pleasant.'

To fully understand the significance of this quotation, the reader needs to understand that both Sky Radio and Voice are radio pro- grammes that attract young people in their twenties. Since most of the patients in the unit are seventy years old or more, it is obvious that the nurse did not acknowledge that the patients might have preferences or indeed that it might be important. Therefore, she made a choice to suit herself (Cochran and Ganong, 1989).

Another nurse said:

I think that it is important that you just give short messages [to the patient] in order not to make the patient think too much about what you're saying to him or her.'

Several investigators have identified that most of the verbal communication given to intensive care patients is of a procedural or information-giving nature and short sentences are often used (Baker and Melby, 1996; Dybwik, 2000). To protect themselves from stress, nurses appear to avoid direct communication or developing a relationship with patients.

When discussing the introduction to the unit and the development of skills necessary to care for an intensive care patient, an inexperienced nurse said:

'I've had permission to work alone a lot already after only two or three weeks, with back-up. You can be in a situation and you're allowed to cope with that situation although it's a complex one. Maybe you have some black spots in your knowledge here and there, but you have the willingness to solve it and learn something.'

The nurse used the expression 'I have had permission to', which suggests that the nurse considered that the concept of being competent, or being seen as competent, had been bestowed by more experienced staff who granted permission. She did not seem to acknowledge the implications of the limitations in her own capacity or competence and what this could mean for the patient and herself.

There was a general feeling of resignation that all nurses, regardless of levels of experience, had to adapt to the conditions that prevailed. One of the nurses stated in the interview:

'If there is an obvious need in the unit, you would perhaps compromise with some things, some principles and so on. Everyone in the unit does so. You can't be the only one backing out when it comes to working a certain shift...'

The nurses in the interview expressed the need for positive feedback and acknowledgement from the management. This would encourage them to gain new knowledge in a positive and inspiring way. Inexperienced nurses appeared to feel pressurised to manage complex patient problems, which for some meant working outside their sphere of competence. They realised that the large number of inexperienced staff put pressure on the more experienced staff. However, none of the participating nurses stated specifically that they felt incompetent or unsure of their decisions. The lack of resources meant that nurses let themselves be pushed beyond their capabilities and that competence appeared to be measured by length of employment instead of through individual professional ability.

According to a Danish nurse, Bente Høy (Melgaard and Dam, 2000), competence can be classified in two ways. Firstly, formal competence is when a nurse is assumed to be competent due to her qualifications and the specific duties she can perform. Secondly, and more importantly, real competence is defined as the ability to apply knowledge to clinical situations, practice and use skills safely, and demonstrate attitudes appropriate to the specific situation. 
Generally, when nurses begin working in the ICU, they often hear the mantra: 'When asked to do something, remember to back out if you are not certain how it should be done'. This is a common phrase used in ICUs across Denmark. Apparently in the unit this statement was not fully respected at the time. Furthermore, the responses from the nurses indicated that they mainly worked from the concept of formal competence. Inexperienced nurses appeared hesitant to contact medical staff. They admitted that they would discuss a clinical problem with other members of their peer group and only ask for help if the situation/problem did not resolve.

One of the nurses stated in the interview:

... We often get together to discuss it [a problem] and try a trick or two before we call and wake up the doctor and quite often it actually goes very well. Other times it doesn't work out well and then we call.'

\section{How can this information be used to develop our practice?}

The findings from this study have enabled us to reflect on our own practice, particularly on how we manage the induction of staff who are new to intensive care nursing. Our findings indicate that levels of competency were assumed, in that experienced members of staff made assumptions about the competency of individuals based on the length of employment rather than an objective assessment of their abilities. This led to situations where staff were allocated more complex patients than they could manage safely and effectively, thus requiring them to work outside their sphere of competence. It has become clear that more rigorous and tailored induction packages are required.

An imbalance in the overall skill mix within the unit may have been unavoidable in this case. However, identification of the overall competency of staff working in the unit allows an assessment of the deficits in skill mix required to provide a safe, effective service and thus inform recruitment campaigns.

A forum for discussion and reflection on practice issues can be provided by the establishment of mentor groups, which should ideally consist of a number of staff with differing levels of competency. These groups should help highlight any gaps in knowledge and skills and therefore identify the education and training needs of staff.

The unit had a small collection of nursing practice guidelines; however, the nurses did not seem to know they existed nor used them to guide their practice. Efforts need to be made to extend these guidelines and to promote their availability, such as placing a copy of the documents in a file at each bed and holding teaching sessions to increase their profile and staff compliance.

It is essential that staff work within their own levels of competency. Staff need to be continually reminded of this and about the implications that working outside their own sphere of competency might mean for themselves, the unit and the patients.

\section{CONCLUSION}

Our project showed that nurses felt isolated and took on responsibilities that fell beyond their level of competence. There was a strong need for nurses to talk about their issues, fears and prob- lems and they felt a designated member of staff should act as an educator/supporter for them.

Some nurses appeared to have very little professional self-awareness, so it was even more important that the unit management could identify and acknowledge the real competence of the individual nurses.

Education and training opportunities are needed to develop a competent workforce, along with specific resources to support such initiatives.

There has been a lot of work done on the 'tacit' knowledge and skill of experts. Perhaps it is time to concentrate efforts on another concept: that of nurses having 'pseudo knowledge' about intensive care - they may know some theory but do not have the experience or resources to apply it.

\section{REFERENCES}

Baker, C \& Melby, V. (1996) An investigation into the attitudes and practices of intensive care nurses towards verbal communication with unconscious patients. Journal of Clinical Nursing 5 (3), 185-192.

Benner, P. (1985) Fra Novice til ekspert. (From novice to expert). Copenhagen: Munksgaard, pp35-49 \& 141-148.

Cochran, J \& Ganong, LH. (1989) A comparison of nurses' and patients' perceptions of intensive care unit stressors. Journal of Advanced Nursing 14 (12), 1038-1043.

Dybwik, K. (2000) Respiratorbehandling - en lærebok for sykepleiere (Ventilation therapy - a textbook for nurses). Oslo: Gyldendal Akademisk.

Fjelland, R. (1995) Vitenskap på egne premisser: vitenskapsteori og etikk for helse-arbeidere (Science in its own terms: Theory of science and ethics for nurses). Copenhagen: Gyldendal, pp190-199.

Fredriksen, S \& Dreyer, T. (1999) Opplevelser av å være intensivpasient (An ICU patient's experiences). Klinisk sygepleje (Clinical Nursing) 2, 109-113.

Gjengedal, E. (1994) Understanding a world of critical illness. University of Bergen: Department of Public Health and Primary Health Care, Division for Nursing Science.

Plough Hansen, H. (1995) I grænsefladen mellem liv og død (In the interface between life and death). Copenhagen: Nordisk Forlag A/S, pp21-30.

Hudak, CM \& Gallo, BM. (1994) Critical Care Nursing - A Holistic Approach. Philadelphia: JB Lippincott Company, pp32-43.

McGuire, BE. Basten, CJ, Ryan, CJ \& Gallagher, J. (2000) Intensive care unit syndrome: a dangerous misnomer. Archives of Internal Medicine 160 (7), 906-909.

Melgaard, E \& Dam, L. (2000) Læring og kultur (Learning and culture) (2). Copenhagen: Udviklings og uddannelsesafdelingen (Department of Education and Development), Bispebjerg Hospital.

Tanimoto, S, Takayanagi K, Yokota H, Yamamoto Y (1999) The Psychological and Physiological Effects of an Intensive-Care Unit Environment on Healthy Individuals. Clinical Performance and Quality Health Care 7 (2), 77-82.

Todres, L, Fulbrook, P \& Albarran, J. (2000) On the receiving end: a hermeneutic-phenomenological analysis of a patient's struggle to cope while going through intensive care. Nursing in Critical Care 5 (6), $277-287$. 